\author{
Proceedings of the $9^{\text {th }}$ International Conference on Applied Informatics \\ Eger, Hungary, January 29-February 1, 2014. Vol. 2. pp. 301-307 \\ doi: 10.14794/ICAI.9.2014.2.301
}

\title{
Birth of Mobile Academy
}

\author{
László Menyhárt, Zoltán Illés, Viktória Heizlerné Bakonyi \\ ELTE IK MOT \\ menyhart@inf.elte.hu, illes@inf.elte.hu, hbv@inf.elte.hu
}

\begin{abstract}
Today, we can say that smart phones and other smart devices are widely spread including smart TVs, which become part of everyday life. Rapid changes of our running world are well noticeable on the dizzying development of IT devices. Appearing installable operating systems on the smart devices there is a necessary requirement to be available for software professionals as well.

It is proofed by the fact that there are more and more job advertisements for experts on this area. Even in the higher vocational education the mobile application development is more pronounced too. It is not acceptable that the universities' IT trainings do not deal with developing possibilities of different devices, and the students meet with this area only as an employee. Naturally, our students in ELTE IK - as possible elsewhere too - could be familiar with the different mobile operating systems and characteristics of application development only on some special courses. Nevertheless these courses are not based on each other and most of them start from the beginning again and again because their mission is not to deepen the knowledge and to create complex applications. Getting to know with other smart or intelligent devices, as smart TV is not presented in these subjects. Of course, we know that the principals of the programming are not changed because of these new devices but there are some new features, which cannot be ignored. We suppose that students have deep IT basic knowledge, the devices and basics of this field are well known them, so they are ready to use and improve it. Our plan is to create a new "Mobil Academy" block, which will be available to our students as a whole block with 16 credits. Creating the syllabus of the new block first, we have to review the basic knowledge from which the topics can be built. Here we think to the content of compulsory, eligible or special courses offered by different departments.

Mobile Academy brings into focus the followings, based on the general available courses:
\end{abstract}

- Mobile platforms

- Reusing source code in multiplatform environment

- Designing and implementing complex projects 
- Today's and future's Smart devices

We do not want to concurrent with the current courses, but to deepen and integrate the student's knowledge in Mobile Academy. Primary aim of us is qualifying experts of professional mobile projects based on confident theoretical knowledge. The proposed topics are listed in the article and we present an example for the effective work.

Keywords: Mobile device, application development, teaching, smart device, education, multiplatform, project

MSC: 97B40, 97Q50, 97Q60

\section{Introduction}

Some years ago it would be unbelievable that within a short time the market of PC-s will be down, but it is the truth for nowadays. The tablets and smart phones are taking their place both in the field of communication via net and in the field of running applications. Let us see a table (Table 1.) showing the device shipments as a proof of our statement.

\begin{tabular}{|l|l|l|l|}
\hline Device Type & $\mathbf{2 0 1 3}$ & $\mathbf{2 0 1 4}$ & $\mathbf{2 0 1 5}$ \\
\hline Traditional PCs & 296.1 & 276.7 & 263.0 \\
\hline Tablets & 195.4 & 270.7 & 349.1 \\
\hline Mobile Phones & $1,807.0$ & $1,895.1$ & $1,952.9$ \\
\hline Other Ultramobiles & 21.1 & 37.2 & 62.0 \\
\hline Total & $2,319.6$ & $2,479.8$ & $2,627.0$ \\
\hline
\end{tabular}

Table 1: Worldwide Device Shipments by Segment (Millions of Units) (source: http://www.gartner.com/newsroom/id/2692318)

The new trend is the appearance of all kind of smart devices in public life from smart TV-s through smart watches to smart glasses. It was stated on the 11th Wearable Technologies Conference 2014 Europe that 2014 would be the year of wearable smart systems.

These new kind of devices require informatics experts who are well informed in these areas as well or who are experts to these special knowledge. In higher education day by day, we had had to face the interest against to the new devices and naturally the programming of them. (The rate of interest is shown in Table 2. through some of the courses) That is why a lot of special courses appeared in the curricula not only in ELTE but most of the programs of other universities programmers trainings as well.

The above-mentioned courses are not built on each other, as they are special, optional ones. They show a lot of very interesting details of mobile application development, but they have a debt in deepening the general knowledge and in giving a wide overview of the field. Our aim was to develop a course block, named Mobile Academy, which has four related subjects. We are sure 


\begin{tabular}{|l|l|l|}
\hline Name of subject & Interested students & Available place \\
\hline C\# on mobile platforms & 62 & 20 \\
\hline $\begin{array}{l}\text { Rich functional mobile and } \\
\text { web application with Flex }\end{array}$ & 29 & 20 \\
\hline $\begin{array}{l}\text { Development of mobile } \\
\text { applications }\end{array}$ & 74 & 37 \\
\hline
\end{tabular}

Table 2: Rate of student's interest on some ELTE mobile courses (collected from ELTE NEPTUN system in 2014 January)

that the same problem came up elsewhere too with different solutions. For example in Óbuda University, there is an Embedded and Mobile Informatics Systems specialization in Informatics Engineering BSC. (http://nik.uni-obuda.hu/hu/ oktatas/mernok-informatikus-bsc). There are several examples from abroad too e.g. at the University of Bradford we can find not only a specialization, but a whole BSC program for mobile programming named Mobile Computing. (http:// www.uk-universities.net/Universities/Programs/Mobile_Computing.html)

\section{The specialties of development}

\subsection{Features of mobile devices}

First of all the developers must get to know thoroughly the general features of mobile devices (we speak not only about phones). In such mobile equipment there are several built in physical devices, which are not used in general PC-s, like cameras, gyroscope, accelerometer, touch screen, GPS etc. - so the programming of them can mean newness for even expert programmers. Besides physical devices, there are some other features, which one has to be also in consideration of. For example the size of screens are smaller, than on PC-s, moreover there are a lot of different size types - so the UI must be overthought thoroughly. At last but not least we have to speak about the fact, that these devices are working from accumulators mainly, so the efficiency of resource usage must be also an important question.

\subsection{Diverse mobile platforms}

The existence of several mobile platforms besides each other can cause a great trouble for developers. Table 3 . will show the rate of different mobile OS in 4Q2013.

It would be good if all application runs over all platforms, - a different platform can mean different developing environment, different programming language, and different libraries - but how it is realizable? Is it possible anyway? 


\begin{tabular}{|l|l|}
\hline Mobile OS & $\mathbf{4 Q 1 3}$ Market Share \\
\hline Android & $78.1 \%$ \\
\hline iOS & $17.6 \%$ \\
\hline Windows Phone & $3.0 \%$ \\
\hline BlackBerry & $0.6 \%$ \\
\hline Others & $0.7 \%$ \\
\hline
\end{tabular}

Table 3: Rate of top 5 smartPhone OS (Source: IDC Worldwide Mobile Phone Tracker, February 12, 2014)

\subsection{Diverse mobile resources}

The capability of hardware resources is absolutely is same. Let us see the nowadays devices. We can find a mobile device with parameters: One core $800 \mathrm{MHz}-1 \mathrm{GHz}$ processor, $256 \mathrm{MB}$ memory, with $320 \mathrm{x} 480$ pixel screen resolution, very limited sensor support. On the other side of course we can find a high end device too.

We made a research about m-learning systems and that time we declared that the mobile devices have limited resources and therefore we have to suggest a special framework, designed to mobile devices. [1] Fortunately today the minimum hardware configuration has nearly the same as it was used a few years ago in a desktop PC environment. This situation is also can be noticed! Let's for example the new Windows Phone 8.1 operating system, this is the first mobile operating system which would coincide, nearly same, as the normal release of Windows 8.1.

\subsection{Convergent software development}

As we saw there are wide range capacity mobile devices, and naturally, there are several ways of acceptable development environment. Basically each operating system has own developer method, environment, preferred programming language. Some of the developers (teams) write their application just for the one-two most spread OS - it is above the $90 \%$ of market. So, they choose to develop the same thing with different tools, which fit the best to the special device and for the need of special consumers. Others use the possibility to run their application in mobile browsers. The advantage of this solution is undoubted, using validated HTML, CSS and Javascript elements the application will work on each mobile device. But what can we do, if we want to use the built in devices? It is a pity, but we are not able to reach these opportunities through browsers. The answer is clear, let us use a framework (e.g. phonegap), which solves the problem instead of us. It offers a way to us to program in HTML and JavaScript, but the framework itself uses native code (for each platforms). What other solutions are there? The reader must know about Mono project and Xamarin studio, with which we can develop in $\mathrm{C} \#$ programming language in Visual Studio or in Xamarin to iOs, Android or Windows Phone. The code-behind, the business-logic can be the same (reusable), but UIs are different naturally. Here we can mention Embarcadero's Firemonkey solution. Using it, we can develop mobile application with $\mathrm{C}++$ or Delphi to Android or to iOS platforms. Summarizing the above-mentioned, we have 
to state, that we have several possibilities, but the real perfect solution, which can be used in each situation does not exist yet! Of course one thing we could notice, the mobile development process has less and less difference to desktop one! The main difference is the screen size, so application needs to create two user interface, one designed to desktop and other designed to mobile device. However we can only design one interface, if we dynamically reinterpret the device context, as for example "bootstrap" does! [2]

As we saw in the previous paragraph, the hardware capacities are enough to host a "full operating system", therefore practically there are no differences between API's too.

\subsection{Other smart devices and the development}

There are several smart devices, and their penetration is increasing. But what does SMART means in this context? Are these devices really smart or do they have only sensors for measurement and applications for reporting technology? From what kind of applications do they become too smart devices? How can we develop such applications?

When the installable operating systems were published the development of this devices became possible. The next step was that more hardware manufacture started to offer small sized and low-cost hardware platforms with enough calculating capacity. These are really available for the wide public and in the education as well. We mention here Intel Edison and Raspberry PI.

\section{Mobile Academy}

Mobile Academy is for MSC students, who are already advanced programmers, so there is no need to teach different programming languages, the usage of different tools, the meaning of team working or algorithmic thinking - we can focus only for the specialties. Developing applications for smart devices do not demand absolute new programing paradigms but only the knowledge of new features and possibilities. Mentioned above, our courses aimed to give a related knowledge for developing applications on smart devices not only for smart phones and for tablets. This idea is mirroring in the curricula created by us. The courses are as they follows next: 1) Mobile platforms, 2) Reusing source code in multiplatform environment, 3) Designing and implementing complex projects, 4) Today's and future's Smart devices.

In the first course, named "Mobile platforms", we show the specialties of different platforms and the students' task to create application for one of the given OS. Therefore, they can learn one of the OS deeply. They have to work in teams, so they have to manage their work with some version controlled team server and use some modern team working method like Scrum with teacher-help.

Next course, named "Reusing source code in multiplatform environment" aims to show how to create reusable code for several platforms, not hiding the difficulties 
in creating the best fit UI for each of them. In this term, the teams have to work with Visual Studio in C\# language.

The third and last course in mobile developing is "Designing and implementing complex projects". During this course, the students get a complex "industry like" task e.g. a game development. Naturally, they have to work in teams and manage their own work.

Due to our aims giving a deep and highly qualified summary of this new area, there is a strict demand towards our students: their application should be so excellent, that at the end of the term the programs can be uploaded to the AppStores

The last, the fourth course is "Today's and future's Smart devices". In the first part of course the devices and their features are shown and after it the students are working. They have to implement an application on various smart devices, as they are advanced programmers, they can choose task for the given ones or to bring some "own problem" as well.

Since this field is a very quickly changing area, newer and newer devices and developing tools are appearing from one day to the other. One of the most difficult task for the university will be to guarantee the proper working conditions.

\section{Summary}

It seems we can say today all devices are going to became smart. Therefore we see our normal mobile phone became smart. Today it is practically impossible to buy an old fashion device. At home there are more and more smart devices around (recent normal home televisions are now practically computers with an additional device, with television tuner). In plants, in factories, in the industry they are used as intelligent controllers for measurement and automation. So smart phones and other smart devices are widely spread including smart TVs, which become part of everyday life. Generally we may notice a classical computer physical size drastically reduced therefore it gives a chance to change all devices (all electrical devices in our environment) to a minimized computer. We see such a modularity appears in a row of computer types like Raspberry Pi, Intel Arduino etc.

We state that the principals of the programming are not changed but there are a few new device features (gyroscope, GPS, etc.), which connect to mini CPU. So the general programming model changes with these new possibilities. Syllabus of Mobile Academy covers the whole platform of the mobile's hardware and software.

\section{References}

[1] ILLÉS, Z., PSENAKOVA, I., HEIZLERNE BAKONYI, V., New perspectives of mlearning, Acta Electrotechnica\&Informatica 8:(pp36-39), 2008

[2] Bootstrap, http://getbootstrap.com, 2014

[3] ALSTON, P., Teaching Mobile Web Application Development: Challenges Faced And Lessons Learned, 
http://sigite2012. sigite.org/?searchterm=mobile+teaching\&presentation= teaching-mobile-web-application-development-challenges-faced-and-lessons-learned, 2012

[4] HALSTEAD-NUSSLOCH, R., REICHGELT, H., Leveraging HCI in Teaching Mobile, 'Anytime and Everywhere' IT", http://sigite2013.sigite.org/?presentation=leveraging-hci-in-teaching-mobile-anytime-and-everywhere-it, 2013

[5] QUINN, C., The Mobile Academy, http://elearnmag.acm.org/featured.cfm? searchterm=mobile+academy\&aid=2094256, 2012

[6] David Thornburg, „Mobile Devices And The Future Of Learning”, http://databus . cetpa.net/2012/07/16/mobile-devices-and-the-future-of-learning/, 2012

[7] Obama, B., „Don't just play on your phone. Program it.”, http://www.wired.com/ wiredenterprise/2013/12/obama-code, 2013

[8] ILLÉS, Z., HEIZLERNE BAKONYI, V., Mobil eszközök az oktatásban és a mobil programozás oktatása, SCIEDU, Nitra, 2013

[9] PSEnAKOVA, I., ILlÉS, Z., SZABÓ, T., HEIZLERNE BAKONYI, V., Mobil világ és mobil programok fejlesztése WP7-re, SCIEDU, Nitra, 2013

[10] HEIZLERNE BAKONYI, V., ILLÉS, Z., MENYHÁRT, L., Viewpoint for the development of teaching contents int he fields of informatics, Acta Didactica, Napocensia, vol. 6. No.2, 2013 